ОПЫТ СИНХРОННОЙ ВИЗУАЛИЗАЦИИ МИНЕРААЬНОЙ ПАОТНОСТИ НИЖНЕЙ ЧЕАЮСТИ БОЛЬНОГО ПАРОАОНТИТОМ НА ТРЕХМЕРНОЙ РЕКОНСТРУКЦИИ.

СОПОСТАВАЕНИЕ КАИНИЧЕСКИХ И РЕНТГЕНОЛОГИЧЕСКИХ МЕТОАОВ ОБСАЕАОВАНИЯ

\section{Актуальность темы}

Компьютерная томография (КТ) как метод диагностики заболеваний пародонта неуклонно внедряется в практическую деятельность стоматологов. Количественная оценка изображения является одним из важнейших преимуществ КТ перед другими методами лучевой диагностики, такими как рентгенография, ультразвуковое исследование, МРТ $[1,2,3,4,6,9,14,15,16]$. Конусно-лучевой компьютерный томограф (КЛКТ) Planmeca фиксирует плотность костной ткани в окнах трех томографических срезов в единицах Хаунсфилда (у. ед., HU). Г. Хаунсфилд принял за единицу отсчета рентгеновской плотности $0 \mathrm{HU}$ плотность дистиллированной воды при стандартном давлении и температуре, а воздуха - за 1024 единиц HU. C помощью этого инструмента определяют показатель, характеризующий ослабление объектом рентгенологического излучения по отношению к дистиллированной воде.

В четвертом окне КЛКТ Planmeca создается трехмерная реконструкция верхней и нижней челюстей. Плотность в окне трехмерной реконструкции исчисляется в единицах значений серого (Grey Values). Шкала КТ-плотностей серого - включает 4096 значений - от -1024 до +3071 единиц Хаунсфилда (HU). Окно трехмерной реконструкции при определении минеральной плотности костной ткани можно рассматривать как окно визуализации плотных структур. По данным литературы, окно визуализации плотных структур ограничено показаниями от 662 до 3071 у. ед., HU (1686-4095 чисел $\mathrm{GV})$ и не имеет отрицательных значений.

Необходимо также учитывать, что окно трехмерной реконструкции - это окно для пространственной оценки неоднородности костной ткани верхней или нижней челюстей. Экран монитора может отображать 256 оттенков серого из 4096

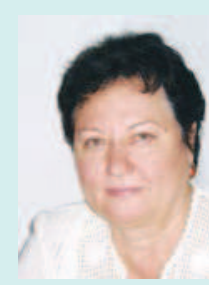

Ронь Г.И.

д.м.н., профессор, зав. кафедрой терапевтической стоматологии ГБОУ ВПО УГМУ, г. Екатеринбург, ugma-zub@yandex.ru

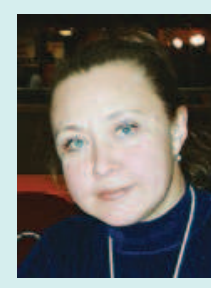

Уварова Л.В. К.М.Н., врач-стоматолог многопрофильной стоматологической клиники ГБОУ ВПО УГМУ, l-uvarova@mail.ru

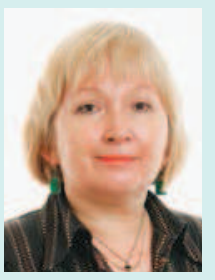

Еловикова Т.М. д.м.н., профессор кафедры терапевтической стоматологии ГБОУ ВПО УГМУ, ugma-elovik@yandex.ru

\section{Резюме}

Рентгенологическая диагностика заболеваний пародонта на конусно-лучевом компьютерном томографе позволяет количественно оценить уровень костной ткани на трехмерном изображении. Методика синхронной визуализации позволяет не только увидеть уровень костной ткани, но и определить ее плотность в условных единицах.

\section{The summary}

Radiological diagnosis of periodontal disease on the cone-beam computed tomography allows to quantify the level of bone on the three-dimensional image. Synchronous imaging technique allows not only to see the level of the bone, but also to determine its density in units. 
$[6,10,11]$. С помощью окна визуализации трехмерной реконструкции осуществляется регулировка яркости и контрастности КТ-изображения таким образом, что на экране монитора в шкале серого цвета видны только ткани требуемого диапазона плотностей. Ткани с меньшей плотностью будут перекрыты черным цветом, ткани с большей плотностью - белым [7].

Учеными уже выявлена плотность при хроническом генерализованном пародонтите легкой степени тяжести (ХГПЛСТ) - 1550-1300 у. ед.; при хроническом генерализованном пародонтите средней степени тяжести (ХГПССТ) - 1300-1108 у. ед.; при хроническом генерализованном тяжелом пародонтите (ХГТП) - 1200-1065 у. ед. [8]. Однако измерения плотности костной ткани проводились точечно и не соотносились со всем массивом костной ткани челюстей $[17,18,19,20,21]$.

В литературе встречаются единичные сообщения, подчеркивающие необходимость и сложность генерализованной количественной оценки поддерживающего аппарата зубов как целостной системы $[5,12,13,14]$.

\section{Цель исследования}

Повышение эффективности диагностики стоматологических больных на основании сопоставления данных клинического и рентгенологического обследования.

\section{Материалы и методы}

Синхронная визуализация как метод определения минеральной плотности нижней челюсти (у. ед. НU) в области томографических срезов с дальнейшим выявлением этой плотности на виртуальной трехмерной реконструкции челюстей.

Для измерения плотности костной ткани в области томографических срезов используют инструмент ROI (region of interest, зона интереса), который может иметь форму круга или овала. Один из показателей инструмента RIQ - минимальное и максимальное значение вокселей (плотностей) в зоне интереса. При этом если брать в зону интереса только костную ткань, максимальное значение отражает минеральную плотность костной ткани или плотность трабекулы. Учитывая, что три томографических среза пресекаются в одной точке, целесообразно находить среднее арифметическое значение минеральной плотности в точке пересечения томографических срезов.

Особенностью трехмерной реконструкции является наличие границы перехода белого цвета в серый - это своеобразная демаркационная линия, виртуальная пустота.

Точка фиксированной минеральной плотности, помещенная в область демаркационной линии, - это то, что больше значения серого на панели инструментов, но меньше значения белого. Если в области трехмерной реконструкции интересующую нас точку поместить в серое поле, то ее значение будет меньше значения серого на панели инструментов и она не будет визуализирована. Если точку интереса перекрыть белым полем, то значение плотности в точке будет больше значения серого на экране в среднем на 256 оттенков. Интересующая нас область визуализируется.

Чтобы приблизительно отразить значение фиксированной минеральной плотности в у. ед. HU, на трехмерной реконструкции нужно перекрыть точку определения плотности (точка интереса) белым цветом. Определить соответствующие числа GV на панели инструментов. Прибавить к числам GV значение видимого экрана - 256 оттенков серого. Затем из полученной суммы необходимо вычесть 1024 единицы.

3D-изображения в большинстве случаев не предназначены для целей диагностики, их главная цель - наглядное представление информации [7].

В случае синхронного выявления фиксированной минеральной плотности (в одной точке) на трехмерной реконструкции челюстей мы можем говорить только о синхронной визуализации участка костной ткани, где искомая нами плотность располагается вблизи демаркационной линии. А плотность неоднородной костной ткани (белый цвет) представлена спектром плотностей от 4095 до интересующей нас фиксированной минеральной плотности (в одной точке).

\section{Описание клинического случая:}

Пацииент 3. 30 лет обратился в многопрофильную стоматологическую поликлинику УГМУ, так как его беспокоил запах изо рта и кровоточивость десны при чистке зубов. Ранее наблюдался y пародонтолога в частной стоматологической клинике. Кровоточивость десны отмечает на протяжении 6 лет. Раз в год обрашается к стоматологам с иелью проведения профессиональной гигиены полости рта.

При осмотре общее состояние больного удовлетворительное. Лицуо пацичента симметричное, региональные лимфатические узль не пальпируются. Функция жевания не нарушена. Мелкое преддверие полости рта. Тяжи в области преддверия полости рта. Уздечки верхней губы, языка, 
нижней губы средние. Слизистая оболочка полости рта: губ, шекк, языка розового извета, блестящая, влажная, без патологических образований. Слизистая оболочка альвеолярных отростков верхней и нижней челюстей ярко-красного цувета, виден над- и поддесневой зубной камень темного ияета. Глубина пародонтальных карманов 3 мм.

Индекс Рассела (ПИ) = 3,5. Зубы подвижны, 1 степень по классификации Miller в модификации Fleszar.

Диагноз: Хронический генерализованный пародонтит легкой степени тяжести. Стадия обострения. Мелкое преддверие полости рта, тяжи в области преддверия полости рта. Деформачии окклюзионной поверхности.

Дополнительно пациенту проведено рентгенологическое исследование на КЛКТ Planтеса.

На КЛКТ нами выявлена следующая рентгеновская ЗДКТ-семиотика: снижение краевых отделов альвеолярных отростков челюстей, разрушение замыкательной кортикальной пластинки в боковых отделах альвеолярных отростков верхней и нижней челюстей, снижение краевых отделов альвеолярных отростков на 1/4 длины корней зубов. Плотность альвеолярных отростков челюстей во фронтальных и боковых отделах челюстей не меняется. Имеются минимально выраженные пристеночные утолщения слизистой оболочки в нижнем отделе верхнечелюстной пазухи справа, что характерно для ЗДКТ-семиотики ХГПССТ.

Денситометрия (определение минеральной плотности кости), по данным конусно-лучевой компьютерной томографии в области тела нижней челюсти справа (в проекции зуба 43), составила:

- аксиальный срез - 1436 у. ед. НU (рис. 1),

- коронарный срез - 1492 у. ед. HU ( рис. 2),

- сагиттальный срез - 1439 у. ед. HU (рис. 3).

Среднее значение минеральной плотности в точке $(1436+1492+1439): 3=1455$ у. ед. $\mathrm{HU}$. (puc. 1, 2, 3).

С изелью визуализации плотности 1455 у. ед. в окне трехмерной реконструкичии челюстей необходимо перекрыть точку пересечения трех срезов большей плотностью-бельм ияветом (рис. 4,5, 6).

В дальнейшем к показателю плотности на панели инструментов необходимо прибавить значение видимого экрана 256 оттенков серого u вычесть 1024 y. ед.

$2223 G V+256-1024=1455$ у.ед. (HU)

Синхронная визуализация фиксированной минеральной плотности нижней челюсти на трех-

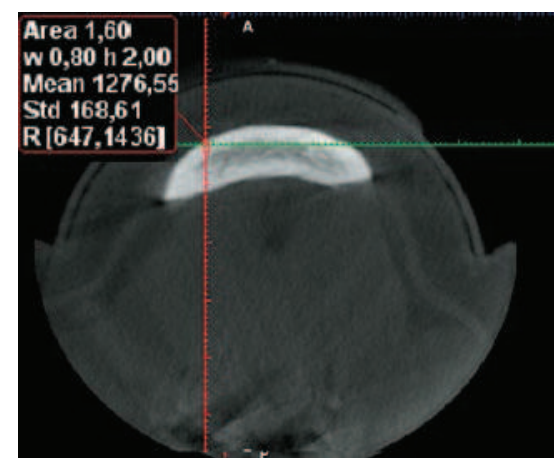

Аксиальный томографический срез

Рис. 1. Определение минеральной плотности тела нижней челюсти в области 43 зуба - 1436 усл. ед. HU

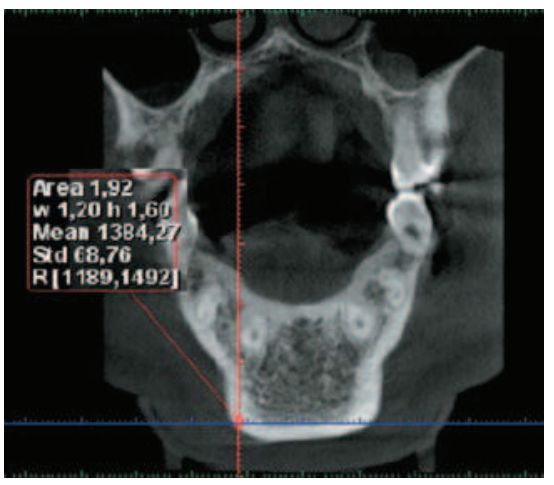

Коронарный томографический срез

Рис. 2. Определение минеральной плотности тела нижней челюсти в области 43 зуба - 1492 усл. ед. HU

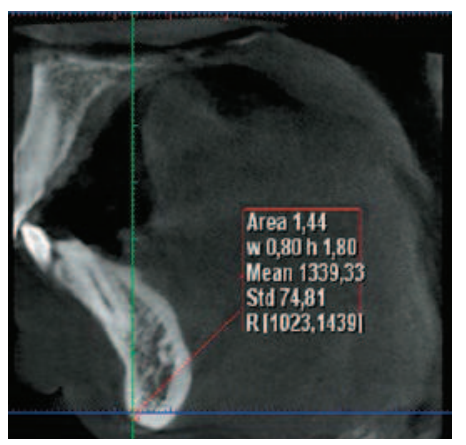

Сагиттальный томографический срез

Рис. 3. Определение минеральной плотности тела нижней челюсти в области 43 зуба - 1439 усл. ед. HU

мерной реконструкции у пацчиента 3. показала, что средняя минеральная плотность тела нижней челюсти 1455 у. ед (HU) и более присутствует в подбородочной области, а также в области тела и угла нижней челюсти справа. Это значение соответствует пародонтиту легкой степени тяжести.

Возможен проиесс обратного перевода чисел GV в у. ед (HU). 


\section{Вывод}

Рентгенологическое исследование на КЛКТ Planmeca уточняет степень тяжести хронического генерализованного пародонтита.

Синхронная визуализация минеральной плотности нижней челюсти на трехмерной реконструкции облегчит восприятие виртуальной модели с возможностью количественной оценки изображения:

- Выявленная (точечно) минеральная плотность в области томографических срезов на трехмерной реконструкции нижней челюсти представлена в белом поле вблизи демаркационной линии (перехода белого цвета в серый) на всем ее протяжении (генерализованно).

- Плотность костной ткани в области трехмерной реконструкции уточняют путем синхронизации этой плотности с данными минеральной плотности томографических срезов.

\section{ЛИТЕРАТУРА}

1. Бондаренко Н.Н. Измерение оптической плотности костной ткани альвеолярного отростка челюстей при заболеваниях пародонта с помощью трехмерной компьютерной томографии / Н.Н.Бондаренко, Е.В.Балахонцева // Казанский медицинский журнал. - 2012. - №4. - С. 660-661.

2. Шлейко В.В., Жолудев С.Е. Компьютерная томография как основной инструмент при планировании и прогнозировании комплексного стоматологического лечения // Проблемы стоматологии. - 2013. - №2. - С. 55-57.

3. Еловикова Т.М. Характеристика клинико-морфометрических параметров зубов и тканей пародонта у больных пародонтитом / Т.М.Еловикова, Л.В.Уварова., Л.Г.Боронина // Материалы XIV международной конференции челюстно-лицевых хирургов «Новые технологии в стоматологии». - СПб, 2009. - С. 80.

4. Мустакимова Р.Ф. Обоснование применения конусно-лучевой компьютерной томографии в диагностике заболеваний пародонта / Р.Ф.Мустакимова, Л.Р.Салеева // X-RAY ART. - 2013. - №3 (02) сентябрь. - С. 36-37.

5. Няшин Ю.И. Взаимодействие зубочелюстной системы с другими системами человеческого организма в рамках концепции виртуального физиологического человека / Няшин Ю.И., Еловикова А.Н., Коркодинов Я.А. и др. // Российский журнал биомеханики. - №3. - 2011. - Т.15, №3 (53). - С. 8-26.

6. Ронь Г.И., Еловикова Т.М. Инновационные технологии в диагностике и лечении воспалительных заболеваний пародонта // Екатеринбург: УГМА, 2011. - С. 278.

7. Хоружик С.А. Основы КТ - визуализации. Часть 1. Просмотр и количественная оценка изображений / С.А.Хоружик, А.Н.Михайлов // Радиология - практика. Продолженное медицинское образование. - 2011. - №3. - С. 62-75.

8. Чибисова М.А. Особенности методики диагностического обследования пациентов с заболеваниями пародонта на конусно-лучевом компьютерном томографе / М.А.Чибисова,

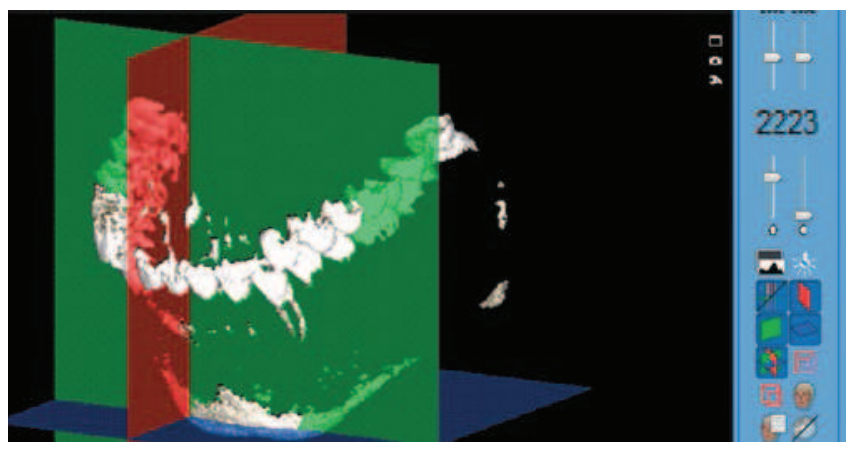

Рис. 4. Трехмерная реконструкция верхней и нижней челюстей с точкой определения минеральной плотности 2223 ед. GV + 256 - 1024 = 1455 у. ед., вид слева

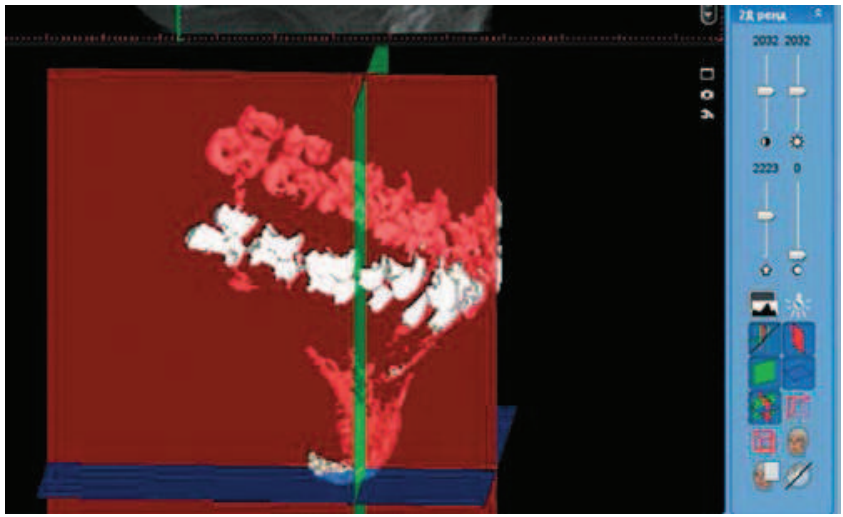

Рис. 5. Трехмерная реконструкция верхней и нижней челюстей с точкой определения минеральной плотности 2223 ед. GV + 256 - 1024 = 1455 у. ед., вид справа

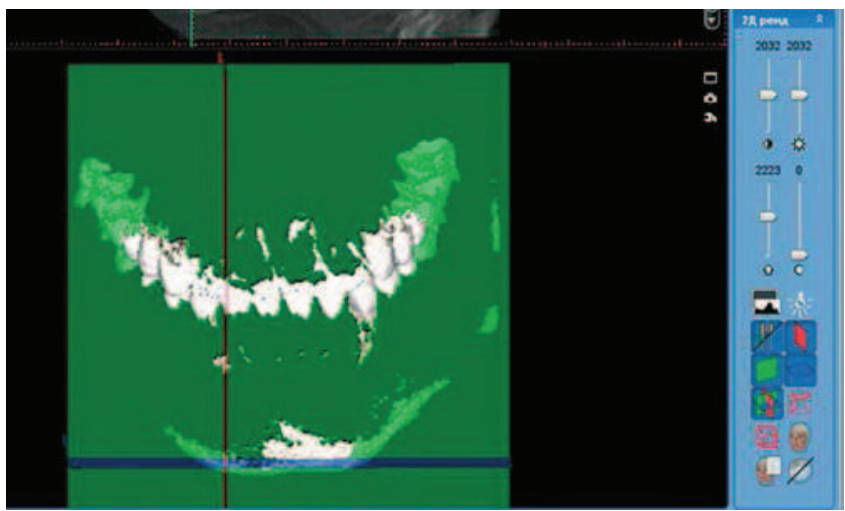

Рис. 6. Трехмерная реконструкция верхней и нижней челюстей с точкой определения минеральной плотности 2223 ед. GV + 256 - 1024 = 1455 у. ед., фронтальный вид 
Л.Ю.Орехова, Н.В.Серова // Институт соматологии. - 2014. №1 (62). - C. 84-87.

9. Шимова М.Е. Применение компьютерной томографии в обследовании пациентов с воспалительными заболеваниями пародонта / Хирургическая стоматология и имплантология. - 2012. - №4. - С. 20-22.

10. Чуйко А.Н. Биомеханика и компьютерные технологии в челюстно-лицевой ортопедии и дентальной имплантологии / А.Н.Чуйко, М.М.Угрин, Р.А.Левандовский и др. Львов: «ГалДент», 2014. - 322 с.

11. Чуйко А.Н. Об особенностях биомеханики многокорневого зуба в норме и при резорбции костной ткани / А.С.Чуйко, Л.В.Уварова // Пародонтология . - 2008 . - №1 (46). - С. 25-39.

12. Уварова Л.В. Влияние биомеханических особенностей тканей зуба на состояние микрофлоры рта и выбор антибактериальной терапии: автореф. дис. ... канд. мед. наук: 14.00.21 / Уварова Людмила Владимировна. - Екатеринбург, 2006. - 22 c.

13. In-Hye Tak. The association between periodontal disease, tooth loss and bone mineral density in a Korean population / Min-Ho Shin, Sun-Seog Kweon, Hae-Sung Nam // J. Clin. Periodontol. - 2014. - Vol. 41. - P. 1139-1144.

14. Jeroen Zweers. Characteristics of periodontal biotype, its dimensions, associations and prevalence: a systematic review /
Renske Z.Thomas, Dagmar E.Slot // J.Clin. Periodontol. - 2014. - Vol. 41. - P. 958-957.

15. Cochran D.L. Inflamation and bone loss in Periodontal Disease / D. L. Cochran. - 2008. - Vol. 79, №8. - P. 1569-1576.

16. Chronic stress may modulate periodontal disease: a study in rats / D.C.Peruzzo, B.B.Benatti, I.B.Antunes [et al.] // J Periodontol. - 2008. - Vol. 79. - P. 697-704.

17. Cross-sectional Study of Vitamin D and Calcium Supplementation Effects on Chronic Periodontitis / D.D.Miley, M.G.Garcia, C.F.Hildebolt [et al.] // Journal of Periodontology. - 2009. - 15 May. - P. 1-11.

18. Bar-Shavit Z. The osteoclast: A multinucleated, hematopoieticorigin, bone-resorbing osteoimmune cell / Z. Bar-Shavit // J Cell Biochem. - 2007. - №102. - P. 1130-1139.

19. Offenbacher S., Barros S.H. Rethinking periodjntal inflammation / S. Offenbacher, S.H. Barros // Journal of Periodontology. - 2008. - №79. - P. 1577-1584.

20. Verdugo F. Bone microbal contamination influences autogenous grafting in sinus augmentation / F.Verdugo, A.Moragues, J.Pontón // Journal of Periodontology. - 2009. - 11 May. - P.1-14.

21. Vascular endothelial growth factor and microvessel density in periodontitis of systemikally healthy and diabetic patiens / S.D.Aspriello, A.Zizzi, G.Lucarini [et al.] // Journal of Periodontology. - 2009. - 29 July. - P. 1-8.

\section{ААЗЕРНЫЙ ТЕРАПЕВТИЧЕСКИЙ СТОМАТОМОГИЧЕСКИЙ АППАРАТ}

\section{AМCT-01 OПTOAAH}

ПРИМЕНЯЕТСЯ АЛЯ ПРОФИААКТИКИ И АЕЧЕНИЯ:

- Кариеса в стадии Аеминерализации и мелового пятна

- Пульпитов и периодонитов

- Заболеваний пародонта

- Заболеваний слизистой оболочки полости рта

- Воспалительных явлений краевого пародонта после ретракции Аесны

- Наминов после наложения протезов, осложнений в ортодонтии

- Стимуляция регенерации костных тканей в Аентальной имплантологии

- Альвеолитов

- Периоститов и ар.

\section{Разработан по рекоменАациям стоматологов}

\section{НАУЧНО-ПРОИЗВОАСТВЕННОЕ ПРЕАПРИЯТИЕ}

\section{"BEHA"}

410033, г. Саратов, пр-т 50 мет Октября, 101

тел./ факс: (8452) 63-37-59, тел.: (8452) 79-71-69

Меаицинский соисполнитель:

ФГБУ "ЦнИИ стоматологии и челюстно-лицевой хирургии"

119982, г. Москва, ул. Т. Фрунзе, 16

e-mail: npp_vend@mail.ru www.npp-vend.ru

www.optodan.rusmed.ru

\section{ТЕХНИЧЕСКИЕ ХАРАКТЕРИСТИКИ:}

Источник излучения - АиоА мазерный полупроводниковый

Амина волны, мкм......................

Импульсная мощность, Вт.......................5

Частота слеАования импульсов, Гц

режим I ................................ 80-100

режим II .............................. 2000-3000

Амительность импульса, нс ......... 40-100

Потребляемая мощность , Вт, $\max$.... 10

Macca, r. ......................................... 600

Габаритные размеры, мм. $60 \times 120 \times 180$

Питание, В/Гц .............................. 220/50 